\title{
Reakcije oksazola i njihovih derivata u pobuđenom stanju. I. dio: Fototranspozicije u prstenu
}

\section{I. Šagud* i M. Šindler-Kulyk}

Zavod za organsku kemiju, Fakultet kemijskog inženjerstva i tehnologije, Sveučilište u Zagrebu, Marulićev trg 20, 10000 Zagreb, Hrvatska

\section{Sažetak}

Heterociklički spojevi važan su dio organske kemije. Oksazol je peteročlani heterociklički spoj s dušikom i kisikom u prstenu te je dio struktura koje se izučavaju i primjenjuju u medicinskoj kemiji, kemiji farmaceutika kao i u kemiji materijala. Oksazolski prsten u pobuđenom stanju reagira pregrađivanjima prstena, za što je predloženo više reakcijskih mehanizama. $U$ ovom dijelu pregleda detaljno je pokrivena literatura koja se odnosi na fotoizomerizacije (fototranspozicije) u prstenu izoksazola, oksazola i benzizoksazola te fototransformacije prstena uz prisutnost kisika (fotooksigenacije). Također je opisano formiranje oksazolskog prstena fotokemijskim putem.

\section{Ključne riječi}

Oksazol, fotokemija, heterocikli, izomerizacija, fotooksigenacije

\section{Uvod ${ }^{* *}$}

Postoji više monografija i preglednih radova u kojima se govori o svojstvima, sintezi i reakcijama oksazola u osnovnom stanju. ${ }^{1-10}$ Gledano kroz povijest oksazoli su prisutni od 1887. godine kada je $A$. R. Hantzsch dao ime do tada maloj skupini spojeva. Oksazoli su peteročlani heterocikli s dva heteroatoma u prstenu, kisikom na položaju 1 te dušikom na položaju 3 ili položaju 2 (slika 1).<smiles>c1cocn1</smiles>

1<smiles>c1ccc2ocnc2c1</smiles>

3<smiles>c1cnoc1</smiles>

2

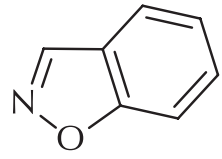

4
Slika 1 - Strukture oksazola (1), izoksazola (2), benzoksazola (3) i benzizoksazola (4)

Fig. 1 - Structures of oxazole (1), isoxazole (2), benzoxazole (3) and benzisoxazole (4)

\footnotetext{
*Autor za dopisivanje: dr. sc. Ivana Šagud e-pošta: isagud@fkit.hr

${ }^{* *}$ Literaturni pregled je obrađen na osnovi literature skupljene u okviru općeg dijela doktorskog rada Ivane Šagud pod naslovom "Sinteza $i$ fotokemija stiren-oksazola, dobivanje novih heteropolicikličkih spojeva", izrađenog na Fakultetu kemijskog inženjerstva i tehnologije 2014 godine u Zagrebu
}

Većina sinteza oksazola tijekom sljedećih stotinu godina bila je usmjerena na sinteze alkilnih i arilnih derivata. Vrlo važna prekretnica u kemiji oksazola dogodila se 1940. godine kad je počelo opsežno istraživanje penicilina. Tijekom toga razdoblja Conforth $i$ sur. razvili su sinteze velikog broja oksazolskih i oksazolonskih derivata. ${ }^{11} 1950$-ih godina N. D. Kondrat'eva je otkrila mogućnost dobivanja piridina u Diels-Alderovoj adiciji oksazola i olefina, ${ }^{12}$ što je navelo Firestona ${ }^{13}$ na istraživanje toga procesa $u$ svrhu sinteze vitamina $\mathrm{B}_{6}$. S obzirom na prisutnost oksazolskog prstena u svim granama kemije i važnost same oksazolske kemije u ovom pregledu opisane su reakcije oksazola u pobuđenom stanju, tj. reakcije do kojih dolazi ozračivanjem ultraljubičastim svjetlom.

\section{Svojstva oksazola}

Prve račune o elektronskoj strukturi oksazola (SCF-MO metoda) proveli su Orloff i Fitts ${ }^{14}$ 1963. godine. Rezultatima tih računa pojasnili su prethodna eksperimentalna mjerenja. Izračunate gustoće $\pi$-elektrona za ugljikove atome $u$ oksazolu idu kako slijedi: $q(5)>q(4)>q(2)$. Berthier $i$ sur. ${ }^{15}$ objavili su rezultate dobivene metodom ab initio, a Roche $i$ sur., ${ }^{16}$ unaprijeđenom metodom LCAO za ukupnu gustoću negativnog naboja $(q)$ kako slijedi: $q(4)>q(5)>q(2)$. Položaj 2 ima najveću gustoću pozitivnog naboja, po svim računima, te je položaj 2 najskloniji napadima od strane nukleofila. ${ }^{1}$ Reaktivnost položaja na oksazolu s elektrofilima ide kako slijedi: $C(5) \geq C(4) \gg C(2)$. Teško je samo na temelju raspodjele gustoće naboja predvidjeti je li položaj 5 ili 4 reaktivniji, međutim većina računa predviđa gustoću negativnog $\pi$-naboja $\left(q_{\pi}\right)$ negativniju na položaju 5 nego na 4, pa bi taj položaj ipak trebao biti malo reaktivniji. Iz računa proizlazi i da su $\sigma$-veze u oksazolu jako polarizirane. 
Formalni naboj $\sigma$-veza u prstenu slijede red elektronegativnosti atoma: $\mathrm{O}>\mathrm{N}>\mathrm{C}$. Naboji $\pi$-veza ne odražavaju taj red elektronegativnosti atoma $\left(q_{\pi}(\mathrm{O})<q_{\pi}(\mathrm{N})\right)$. Polarizacija $\pi$-veza suprotna je od polarizacije $\sigma$-veza, međutim ukupnom distribucijom naboja dominiraju $\sigma$-veze. Poznavanje raspodjele gustoće elektronskog oblaka unutar samog prstena oksazola iznimno je bitno za razlučivanje mehanizama njegova reagiranja u pobuđenom stanju.

\section{Reakcije fototranspozicije}

\subsection{Fototranspozicije izoksazola i benzizoksazola}

Reakcije fotopregrađivanja izoksazola u oksazole proučavali su B. Singh i E. F. Ullman ${ }^{17,18}$ još 1966 . godine. Na primjeru 3,5-difenilizoksazola (5) proučavali su reakcije fototranspozicije izoksazola u oksazol 7. Otkriveno je da osim oksazola 7 u reakciji nastaju i određene količine azirina 6, koji je moguće daljnjim osvjetljavanjem na valnoj duljini od $254 \mathrm{~nm}$ prevesti u 7 , dok se osvjetljavanjem na valnim duljinama većim od $300 \mathrm{~nm}$ vraća u izoksazol 5 (shema 1).

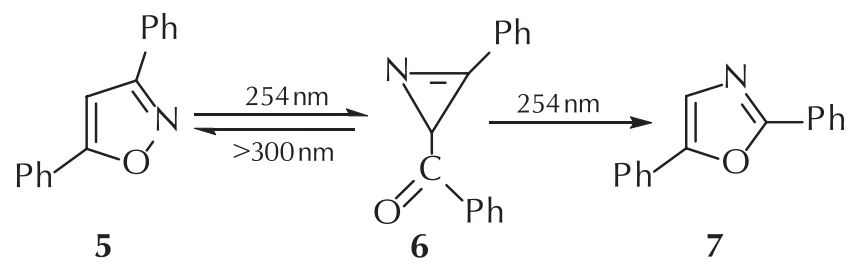

Shema 1 - Fototranspozicija 3,5-difenilizoksazola (5) Scheme 1 - Phototransposition of 3,5-diphenylisoxazole (5)

Autori su uvidjeli da sastav smjese nakon fotokemijske reakcije ovisi o valnoj duljini te su pretpostavili da se radi o selektivnom pobuđivanju dva različita kromofora na azirinskom međuproduktu. Nakon pobude jednoga od kromofora slijedi molekulsko pregrađivanje koje je brže od prijenosa energije s jednog kromofora na drugi. Pobuđivanje benzoilnog kromofora (prijelaz $n \rightarrow \pi$ ) događa se na valnim duljinama većim od $300 \mathrm{~nm}$ te je odgovorno za vraćanje azirina 6 natrag u izoksazol 5. Oba kromofora apsorbiraju energiju na valnoj duljini od $254 \mathrm{~nm}$ te je pretpostavka da je pobuđivanje ketiminskog kromofora ono koje vodi u oksazolski produkt 7.

Benzizoksazoli se ponašaju slično kao 5-feniloksazoli te slijede put preko izonitrilnog otvorenog međuprodukta. ${ }^{19,20}$ Benzizoksazol (4, slika 1) fotokemijski reagira, pri čemu dobivena smjesa nakon fotokemijske reakcije sadrži benzoksazol (3) i 2-cijanofenol.

Desetak godina kasnije Tanaka $i$ sur. ${ }^{21}$ studirali su mehanizam fototranspozicije izoksazola pomoću teoretskih proračuna ab initio metodom $\mathrm{MO}-\mathrm{Cl}$ za izoksazol (2) (shema 2).

Fotoizomerizacija izoksazola može se opisati na sljedeći način. U prvom stupnju izoksazol u najnižem stanju ${ }^{1}\left(n \pi^{*}\right)$ prelazi u azirinski međuprodukt u osnovnom stanju preko

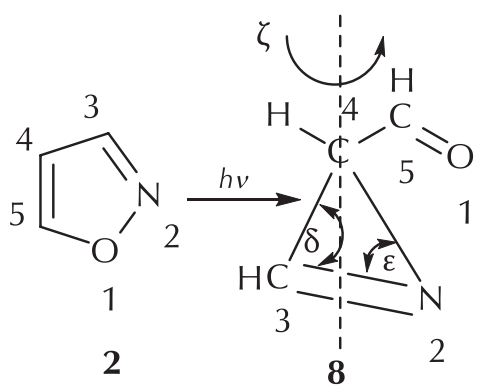

Shema 2 - Fototranspozicija izoksazola (2) Scheme 2 - Phototransposition of isoxazole (2)

torzijske deformacije $\mathrm{N}(2)-\mathrm{C}(3)-\mathrm{C}(4)-\mathrm{C}(5)$ koja vodi pucanju veze $\mathrm{O}(1)-\mathrm{N}(2)$ i istodobnom stvaranju nove veze $\mathrm{N}(2)-\mathrm{C}(4)$. U drugom stupnju dolazi do deformacije kuta veze $\mathrm{N}(2)-\mathrm{C}(3)$-C(4) u stanju $\mathrm{T}_{1}$ (u koje se dolazi preko međusustavnog križanja iz stanja $S_{1}$ ) koje uzrokuje pucanje veze $N(2)-C(4)$. Elektroni na atomima $\mathrm{O}(1)$ i $N(2)$ sparuju se i formiraju vezu O(1)-N(2) i nastaje izoksazol. U trećem stupnju na azirinskom međuproduktu u stanju $\mathrm{S}_{2}$ dolazi do pucanja veze $C(3)-C(4)$ preko deformacije kuta veze $C(3)$ $\mathrm{N}(2)-\mathrm{C}(4)$. Nakon toga dolazi do međusustavnog križanja iz stanja $S_{2}$ u $T_{1}$ te do stvaranja oksazola iz stanja $T_{1}$. Dakle, azirinski međuprodukt ima dva različita reaktivna stanja $\left(S_{1}\right.$ i $\mathrm{S}_{2}$ ) koja su lokalizirana na kromoforima $\mathrm{C}=\mathrm{O}$ i $\mathrm{C}=\mathrm{N}$ i vode u različite produkte reakcije preko različitih reakcijskih putova ovisno o valnoj duljini kojom se osvjetljava.

Pavlik i sur. ${ }^{22}$ izučavali su fototranspozicije pirazola i izotiazola te proširili proučavanje fotokemije na izoksazole i to na primjeru 4- i 5-fenilnih monosupstituiranih izoksazola. Kod fototranspozicija pirazola i izotiazola zaključili su da one uključuju dva kompetitivna puta, put A preko elektrocikličkog zatvaranja prstena i put B preko kidanja veze između dva heteroatoma (shema 3 ).

Već je prije dokazano da fotokonverzija 3,5-difenilizoksazola u 2,5-difenilizoksazol ide preko 3-benzoil-2-fenilazirinskog međuprodukta (shema 1). Supstituent u položaju 3 na prstenu izoksazola vodi dodatnoj termičkoj stabilizaciji azirinskog prstena kojemu je taj supstituent u položaju 2, pa su ti derivati najviše proučavani.

Osvjetljavanjem 5-fenilizoksazola (9) nastala je smjesa dvaju produkata, 5-feniloksazol (10) i benzoilacetonitril (11) (shema 4). Dakle, spoj 9 daje produkt i fototranspozicije i otvaranja prstena. 5-fenilizoksazol (9) ne prati put A fototranspozicije, već put B, dajući fototranspozicijski produkt $\mathrm{P}_{4}$ (sheme 3,4).

Pregrađivanje 9 u 10 (shema 3, produkt $\mathrm{P}_{4}$ ) uključuje formalnu izmjenu atoma N(2) i C(3). Atomi C(3) i C(4) imaju na sebi vodikove atome, pa nije moguće razlikovati je li došlo do njihove zamjene u produktu. Da bi dokazali kako se izomerizacija zbilja događa preko puta B, a ne nekog kompliciranijeg koji uključuje i izmjene između atoma $\mathrm{C}(3)$ i C(4), autori su u studiju uvrstili 4-deutero-5-fenilizoksazol (12), u kojem je svaki od atoma u prstenu moguće jasno razlikovati. Rezultat je pokazao da je proton C(3) iz 


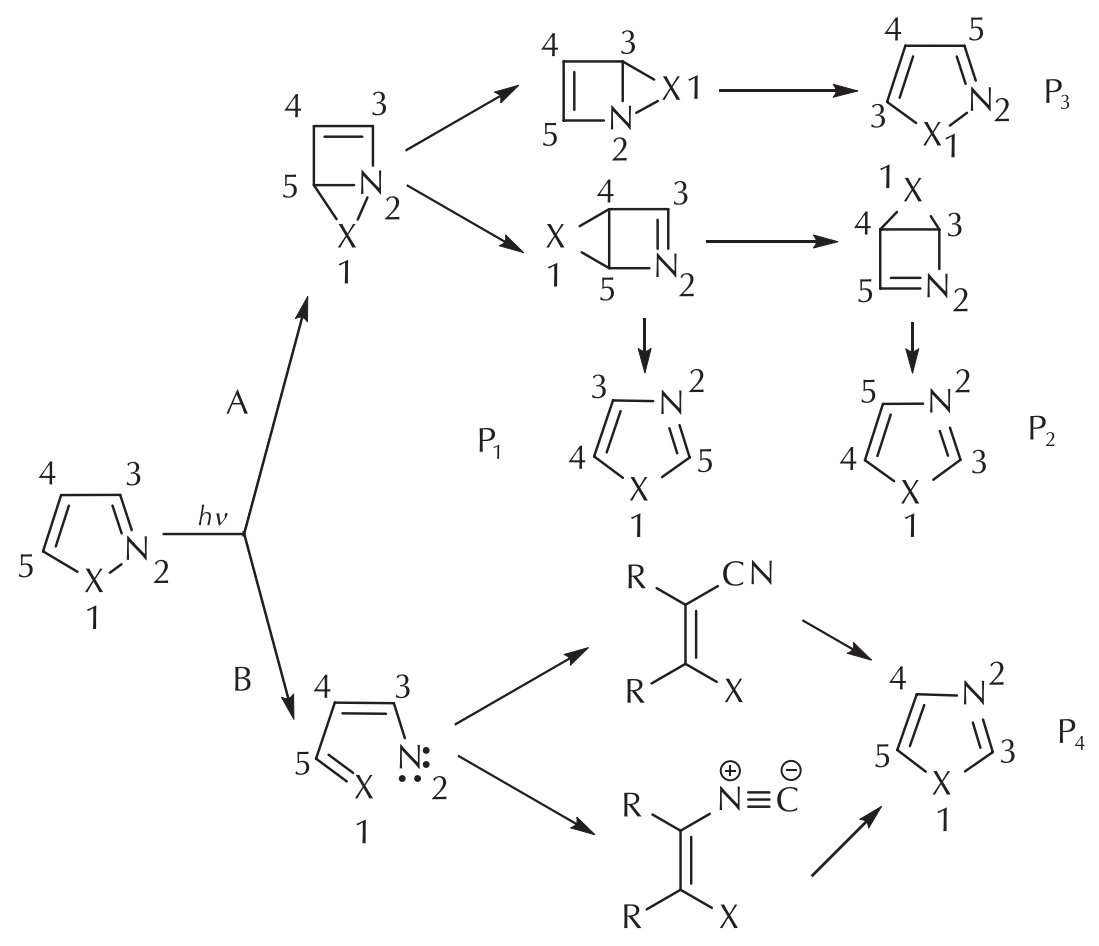

Shema 3 - Dva puta fototranspozicije azola

Scheme 3 - Two pathways of phototransposition of azoles

$\overbrace{\mathrm{O}} \underset{\mathrm{N}}{\stackrel{h v}{\mathrm{CH}_{3} \mathrm{OH}}}$

9<smiles>c1ccc(-c2cnco2)cc1</smiles>

10<smiles>N#CCC(=O)c1ccccc1</smiles>

11
Shema 4 - Fotokemijska reakcija 9

Scheme 4 - Photochemical reaction of 9

spoja 12 transponirao na položaj C(2) u prstenu te je nastao produkt 4-deutero-5-feniloksazol (13) (shema 5).<smiles>[2H]c1c(-c2ccccc2)on1C</smiles>

12<smiles>[2H]c1nc(C)oc1-c1ccccc1</smiles>

13
Shema 5 - Fotokemijska reakcija 12

Scheme 5 - Photochemical reaction of $\mathbf{1 2}$
Time je potvrđeno da se fototranspozicija odvija samo preko izmjene $\mathrm{N}(2)-\mathrm{C}(3)$, kao što je pokazano u putu $\mathrm{B}$. $\cup$ studij fototranspozicije autori su dodali i 4-metil-5-fenilizoksazol 14 (shema 6). Početni spoj dao je dva produkta 15 i 16 analogna produktima osvjetljavanja spoja 9, što potvrđuje da $\mathbf{1 4}$ također reagira po reakcijskom putu B.<smiles>Cc1cnoc1-c1ccccc1</smiles>
14<smiles>Cc1ncoc1-c1ccccc1</smiles>
15<smiles>CC(C#N)C(=O)c1ccccc1</smiles>

16
Shema 6 - Fotokemijska reakcija 14

Scheme 6 - Photochemical reaction of 14

U studij je uključen i 5-fenil-3-(trifluorometil)izoksazol 17. Kao što je vidljivo iz sheme 7 , taj spoj reagira kao i prethodni po reakcijskom putu B pri čemu nastaje oksazol 18 koji je za reakciju provedenu u acetonitrilu i jedini produkt. Ako se reakcija provodi u metanolu, tada nastaje i smjesa (E)- $\mathrm{i}(Z)$-2-metoksi-2-(trifluorometil)-3-benzoilaziridina $(\mathbf{1 9 a}, \mathbf{b})$. 


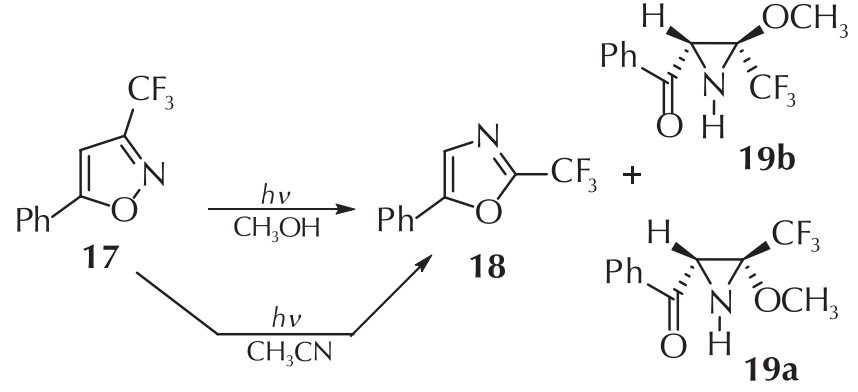

Shema 7 - Fotokemijska reakcija 17

Scheme 7 - Photochemical reaction of 17

Autori pretpostavljaju da aziridini 19 nastaju preko fotokemijski generiranog azirina koji na sebe veže metanol ili se pregrađuje u oksazol 18. Trifluorometilna skupina je elektron-odvlačeća skupina te ona čini azirin podložnijim nukleofilnoj reakciji s metanolom.

Nadalje, reakcija 4-fenilizoksazola (20) daje samo oksazol kao produkt transpozicije, dok 5-metil-4-fenilizoksazol (21) osvjetljavanjem daje 5-metil-4-feniloksazol (22) i $\alpha$-fenilacetoacetonitril (23). Autori su ustanovili da je fototranspozicija 4-fenilizoksazola analogna fototranspoziciji 4-fenil-tiazola i pirazola, dok se 5 -fenil-supstituirani izoksazoli ponašaju drugačije. Za razliku od tiazola i pirazola kod kojih postoji kompeticija između puta A i puta B (shema 3), kod izoksazola reakcije idu isključivo putem $B$, odnosno dolazi samo do izmjene atoma $\mathrm{N}(2)-\mathrm{C}(3)$ na prstenu. Općenito fotokemijska pobuda izoksazola rezultira u cijepanju veze O-N, pri čemu nastaje nitren B za koji je moguće zamisliti više reakcijskih putova (shema 8).

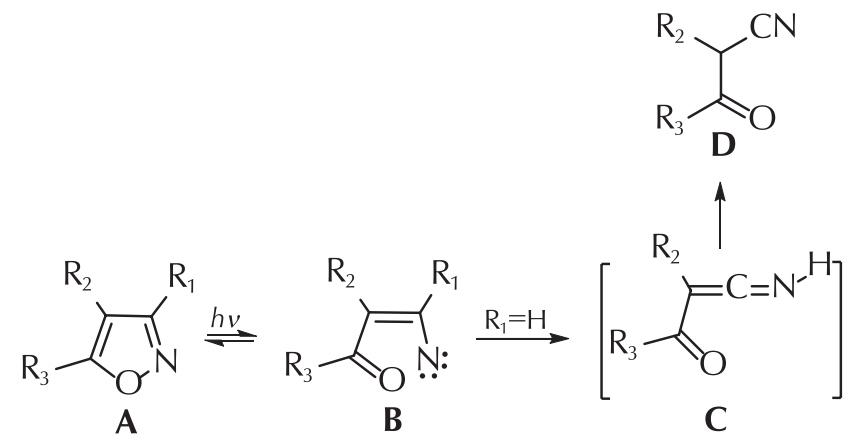

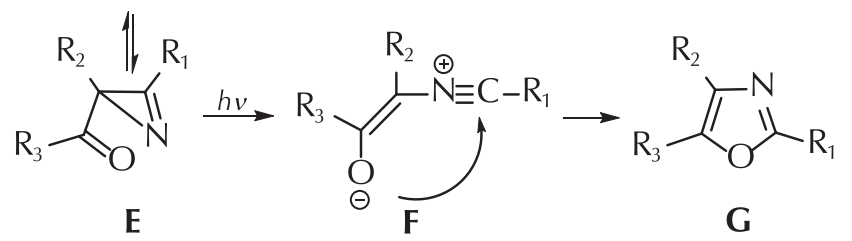

Shema 8 - Mehanizam fototranspozicije izoksazola Scheme 8 - Mechanism of phototransposition of oxazoles
Vinilnitren može reciklizirati u početni izoksazol A, a kada je $R_{1}=H$, može prijeći u ketonitril $\mathbf{D}$ preko ketenimina C. Vinilnitren B također može biti u termičkoj ravnoteži s ketoazirinom $\mathbf{E}$ koji se dalje može fotokemijski pregraditi u oksazol G preko nitril-ilida F. $\beta$-Ketovinilnitren B koji je ključni međuprodukt u ovom mehanizmu može biti generiran eliminacijom dušika iz vinil-azida. Da bi dokazali mehanizam, autori su sintetizirali 3-azido-1-fenilpropen-1-on (24) te istražili njegove termičke i fotokemijske reakcije (shema 9).

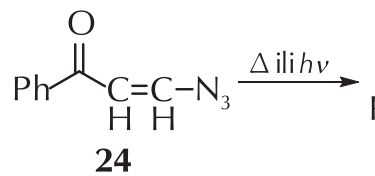<smiles>c1ccc(-c2ccno2)cc1</smiles><smiles>c1ncc(-c2cnco2)o1</smiles><smiles>N#CCC(=O)c1ccccc1</smiles>

Shema 9 - Fotokemijska/termička reakcija $\mathbf{2 4}$

Scheme 9 - Photochemical/thermal reaction of $\mathbf{2 4}$

Glavni produkt termolize spoja $\mathbf{2 4}$ je nitril $\mathbf{1 1}$. Glavni produkt fotolize azida je oksazol 10. Rezultati su pokazali da 3-azido-1-fenilpropen-1-on (24), koji nastaje fotokemijski iz azida, može ciklizirati u 5 -fenilizoksazol (9), a može se i pregraditi u 5-feniloksazol (11).

U najnovije vrijeme studij mehanizma fototransformacija prstena izoksazola razvija se zahvaljujući suvremenim tehnološkim dostignućima. Primjenjuju se moderne računske metode i vrlo kratka vremena osvjetljavanja laserima u kriogenim matricama uz praćenje tijeka reakcije spektroskopskim metodama.

M.-D. Su ${ }^{23,24}$ istražuje izomerizacije izoksazola i benzizoksazola pomoću CASSCF i MP2-CAS računskih metoda. Stariji mehanizam ${ }^{22,25,26}$ za te reakcije bio mehanizam je ciklizacije-izomerizacije (shema 3) koji uključuje prvotno nastajanje bicikličkog međuprodukta nakon kojeg slijedi [1,3]-pomak dušika u sekundarni biciklički međuprodukt koji podliježe otvaranju azirinskog prstena u produkte fototranspozicije $\left(\mathrm{P}_{1}-\mathrm{P}_{3}\right)$. Ti međuprodukti nisu nikad zamijećeni, te je autor predložio drugi, izravni mehanizam preko stožastog presjeka (Cl). Prema dijagramu korelacija stanja reakcija se odvija usklađenim mehanizmom te se dobiva produkt u osnovnom stanju.

U novije vrijeme C. $M$. Nunes $i$ sur. ${ }^{27-30}$ također rade na razjašnjavanju mehanizma fotokemije izoksazola i benzizoksazola. Autori upotrebljavaju lasere uskog UV spektra ne bi li "ulovili" neki od međuprodukata u procesu i time dokazali da sam proces možda i ne ide izravnim putem. ${ }^{23,24}$ Izoksazoli i benzizoksazoli izolirani su u kriogenoj matrici te osvjetljavani laserima uskog spektra UV zračenja, kao metoda identifikacije primijenjena je infracrvena spektroskopija. Pri tim uvjetima otkriveni su do tada neidentificirani međuprodukti (shema 10). Kod nesupstituiranog izoksazola (2) nije došlo do pregradnje u oksazol (1), već je razgradnja izoksazola do ketena $32 \mathrm{i} \mathrm{HCN}$ bila dominantan proces pri valnim duljinama $\lambda=240-238 \mathrm{~nm}$ (shema 10). ${ }^{27}$ 


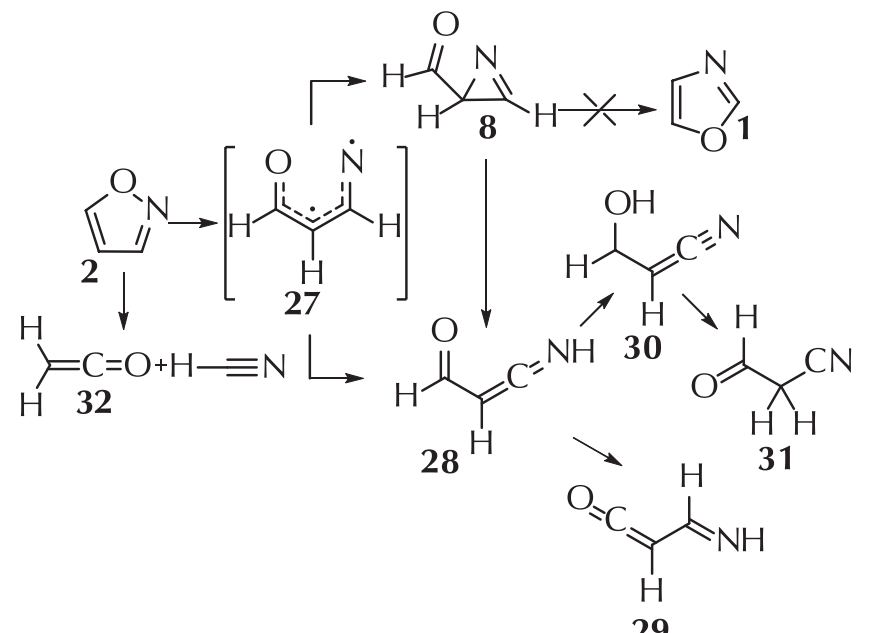

maciju 3-formilketenimina (28) u 3-hidroksipropenitril 30 i imidoilketen 29. Osvjetljavanje na $\lambda=280 \mathrm{~nm}$ i $\lambda=240 \mathrm{~nm}$ omogućilo je identifikaciju 3-oksopropanitrila 31 (shema 10). Time su utvrdili postojanje reaktivnog "neulovljivog" vinilnitrena 27. Vinilnitreni su prihvaćeni kao reaktivni međuprodukti u kemiji izoksazola ${ }^{27-31,36}$ iako zbog svoje visoke reaktivnosti nisu eksperimentalno zamijećeni. Daljnjim istraživanjima fotoizomerizacije na nesupstituiranom benzizoksazolu (4) identificirali su spiro- $2 \mathrm{H}$-azirin (33) i ketenimin (32) kao međuprodukte, što je dodatan dokaz postojanja vinilnitrena (shema 11). ${ }^{30}$

Kod supstituiranih izoksazola ${ }^{28,32}$ fotoizomerizacija ide primarno do azirina (37) i ketenimina (38) nastalih preko vinilnitrena (36), dok se produljenim osvjetljavanjem formiraju dva dodatna fotokemijska produkta koji su identificirani kao nitrililid (38) i supstituirani oksazol (39) (shema 12).

Shema 10 - Predloženi reakcijski putevi i mehanizmi za izoksazol 2

Scheme 10 - Reaction pathways and mechanism for isoxazole $\mathbf{2}$

Osvjetljavanje na $330 \mathrm{~nm} \leq \lambda \leq 340 \mathrm{~nm}$ inducira transformaciju 2-formil-2H-azirina (8) u 3 -formilketenimin (28). Osvjetljavanje na $310 \mathrm{~nm} \leq \lambda \leq 318 \mathrm{~nm}$ inducira transfor-

\subsection{Fototranspozicije oksazola}

Maeda i Kojima proučavali su fotoinducirane transpozicije 2,5-difeniloksazola ${ }^{33}$ još 1969. godine. Osvjetljavanjem 2,5-difeniloksazola (7) nastaju 3,5-difenilizoksazol (5), 2,4-difeniloksazol i 4,5-difeniloksazol. Međuprodukti su 2-benzoil-3-fenil-azirin i 1-benzoil-2-fenil-azirin. Nisu<smiles>C=C=c1cc(CC)ccc1=C=N</smiles>

Shema 11 - Fotokemija benzizoksazola (4) u matrici s argonom Scheme 11 - Photochemistry of benzoisoxazole (4) in an argon matrix<smiles>CC#[N+][C@H]([18OH])C(C)=O</smiles>

Shema 12 - Fotokemijska izomerizacija supstituiranog izoksazola 35

Scheme 12 - Photochemical isomerization of substituted isoxazole 35 
uspjeli izolirati niti jedan od međuprodukata. Isti autori proučavali su i fotokemiju 2-feniloksazola $\mathbf{4 0}^{34}$ (shema 13 ). Prilikom osvjetljavanja 2-feniloksazola (40) uspjeli su izolirati 3-fenil-2H-azirin-karbaldehid (41).

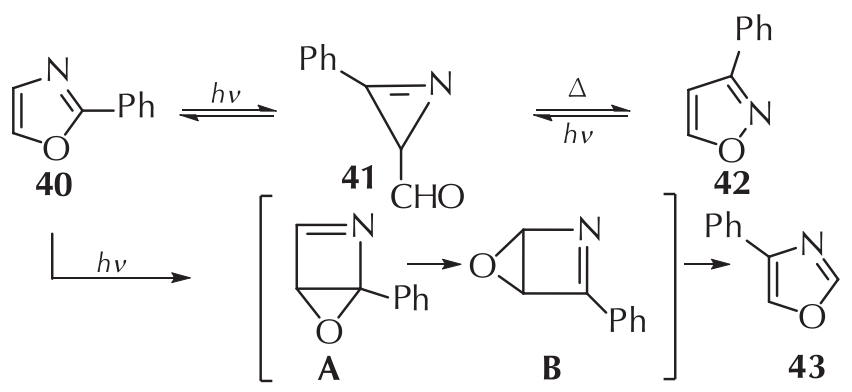

Shema 13 - Fototranspozicija 2-feniloksazola $\mathbf{4 0}$

Scheme 13 - Phototransposition of $\mathbf{4 0}$

Tanaka i sur. su još 1983. godine primjenjivali račune MO$\mathrm{Cl}$ ab initio kako bi objasnili mehanizam fototranspozicije oksazola. ${ }^{35}$ Odmah je bilo jasno da je mehanizam znatno složeniji od fototranspozicije izoksazola i nije moguće jednostavno objašnjenje preko mehanizma koji uključuje kontrakciju prstena do azirina pa natrag ekspanziju u oksazol. Predložili su dva tipa reakcija kod fototranspozicije oksazola. Tip A u kojem dolazi do izmjene dva susjedna atoma i tip B kad dolazi do transpozicije između položaja 2 i 4 na prstenu te položaja 3 i 5 na prstenu (shema 14). Supstituenti na prstenu i otapalo također igraju ulogu prilikom fototranspozicija. Kao modelni spoj upotrijebili su oksazol (1). U prijašnjim istraživanjima pretpostavljalo se da su međuprodukti u tim transpozicijama azirini, od kojih su neki čak i izolirani u reakcijskim smjesama (shema 13).

Autori su metodom $\mathrm{MO}-\mathrm{Cl}$ ab initio računali energetske profile za sve reakcijske putove te međuprodukte i konačne produkte te su predložili četiri moguća puta na temelju provedenih računa. Jedan od faktora koji kontrolira tijek reakcije je i aromatski supstituent (shema 15).

Kad postoji aromatski supstituent na atomu C(2) ili C(5) kao u spojevima $\mathbf{4 4 a}$ ili $\mathbf{4 4 b}$, favorizirana je reakcija na-<smiles>[R]c1cnc([R])o1</smiles>

Shema 15 - Fototranspozicija 2,5-aril supstituiranih oksazola Scheme 15 - Phototransposition of 2,5-aryl substituted oxazoles

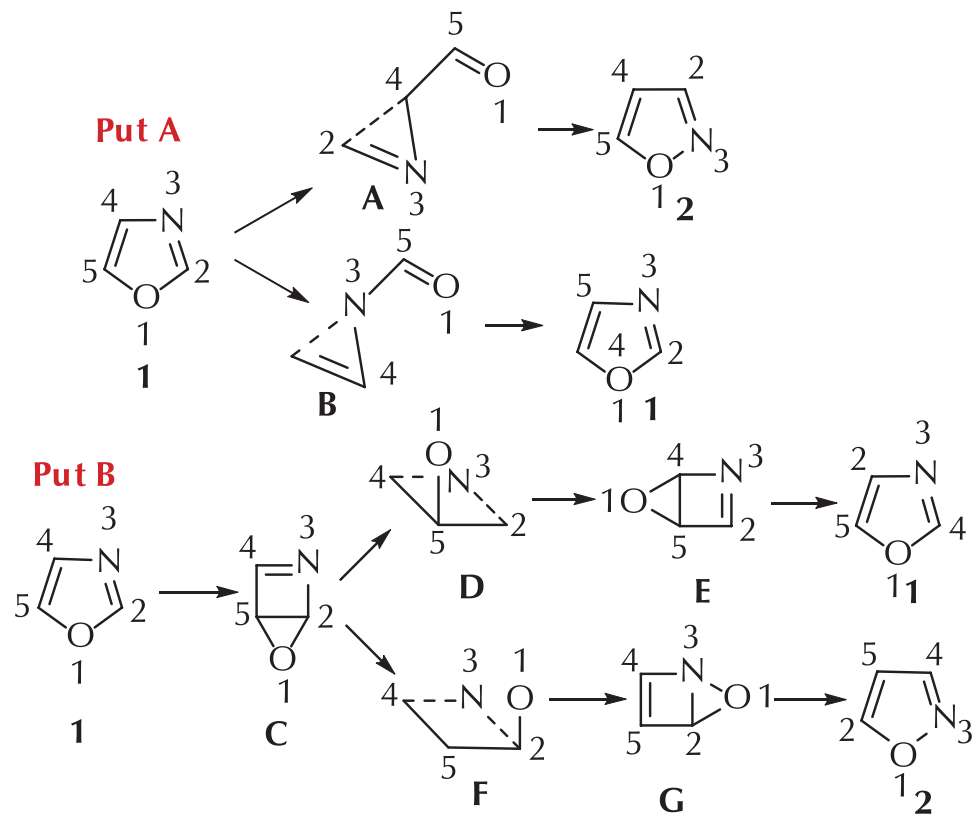

Shema 14 - Mehanizmi fototranspozicije 1

Scheme 14 - Mechanism of phototransposition of 1 
stanka bicikličkog međuprodukta 45. Međuprodukt 46 ima konjugaciju između aromatskog supstituenta i dijela $\mathrm{C}(2)-\mathrm{N}(3)-\mathrm{C}(4)$, dok kod 49 te konjugacije nema. Takva konjugacija stabilizira to prijelazno stanje i snižava energetsku barijeru. Najnovijim teoretskim istraživanjima 2016. godine $X$. Yu i sur. ${ }^{36}$ potvrdili su energetske putove i međuprodukte.

\section{Fotokemijske oksidacije oksazola}

Reakcije fotokemijske oksidacije organskih spojeva mogu se provesti na više načina, a put ovisi o prirodi pobuđenog stanja reaktivnog kisika. Fotokemijske oksidacije "tipa II" odnose se na procese kod kojih je kisik u prvom singletnom elektronskom pobuđenom stanju i reagira sa supstratom koji je u osnovnom stanju. Takav singletni kisik može nastati prijenosom energije iz singletnog ili tripletnog senzibilizatora. Te reakcije vrlo su brze i selektivne. Gledano sa strane sintetske kemije najvažnije su [4+2]- i [2+2]-adicije te oksidacije heteroatoma. Singletni kisik najčešće je generiran u otopini iz molekula kisika i prikladnog senzibilizatora. Gollnick i sur. ${ }^{37,38}$ opisali su reakcije fotoinducirane [4+2]-adicije singletnog kisika na oksazole, pri čemu nastaju odgovarajući endoperoksidi (shema 16).

Kinetička mjerenja pokazala su da navedeni oksazoli lako reagiraju sa singletnim kisikom $\left({ }^{1} \mathrm{O}_{2}\right)$. Brzina reakcije usporediva je $\mathrm{s}$ istovjetno supstituiranim furanima, a neovisna je o upotrijebljenom otapalu. Opisana je i nestabilnost nastalih endoperoksida 54a-f te njihove transformacije pod utjecajem temperatura viših od $-30{ }^{\circ} \mathrm{C}$.

Griesbeck i sur. ${ }^{39}$ su 2005. godine opisali fotokemijske oksidacije 5-metoksioksazola (55) u krutom stanju (shema 17).

Upotrijebili su nano-spremnike od polistirena, te na taj način izbjegli upotrebu otapala. S obzirom na to da je izvor

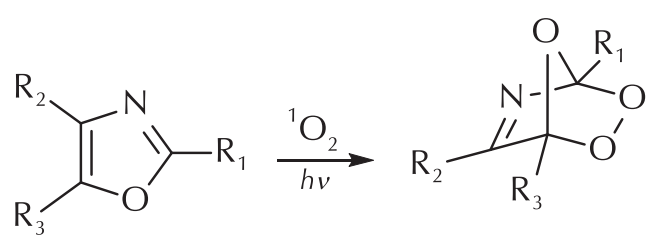

5 2: $\mathrm{R}_{1}=\mathrm{H}, \mathrm{R}_{2}=\mathrm{R}_{3}=\mathrm{CH}_{3}$

$54 a-f$

7: $\mathrm{R}_{1}=\mathrm{R}_{3}=\mathrm{Ph}, \mathrm{R}_{2}=\mathrm{H}$

53 a : $\mathrm{R}_{1}=\mathrm{R}_{3}=\mathrm{CH}_{3}, \mathrm{R}_{2}=\mathrm{H}$

b: $\mathrm{R}_{1}=\mathrm{R}_{2}=\mathrm{CH}_{3}, \mathrm{R}_{3}=\mathrm{H}$

c: $\mathrm{R}_{1}=\mathrm{CH}_{3}, \mathrm{R}_{2}=\mathrm{H}, \mathrm{R}_{3}=\mathrm{Ph}$

d: $\mathrm{R}_{1}=\mathrm{CH}_{3}, \mathrm{R}_{2}=\mathrm{R}_{3}=\mathrm{Ph}$

Shema 16 - Reakcija [4+2] adicije singletnog kisika na oksazole Scheme $16-[4+2]$ addition reaction of singlet oxygen with oxazoles

singletnog kisika molekula kisika, a izvor energije vidljiva svjetlost, te reakcije imaju velik prosperitet unutar područja "zelene kemije". Oni upotrebljavaju tzv. mikroreaktor u kojemu je senzibilizator ugrađen u polimer u čijim šupljinama je i supstrat pravilno raspoređen.

\section{Fotokemijska sinteza oksazolskog prstena}

\subsection{Sinteza 5-(2,2-difeniletenil)-2,4-difeniloksazola}

Mori i Maeda ${ }^{40}$ su prilikom fotokemijske reakcije 2,4,4,6-tetrafenilpiridin-3(4H)-ona (58) u benzenu iz reakcijske smjese, uz 3-hidroksi-2,4,5,6-tetrafenilpiridinom (59), ne-

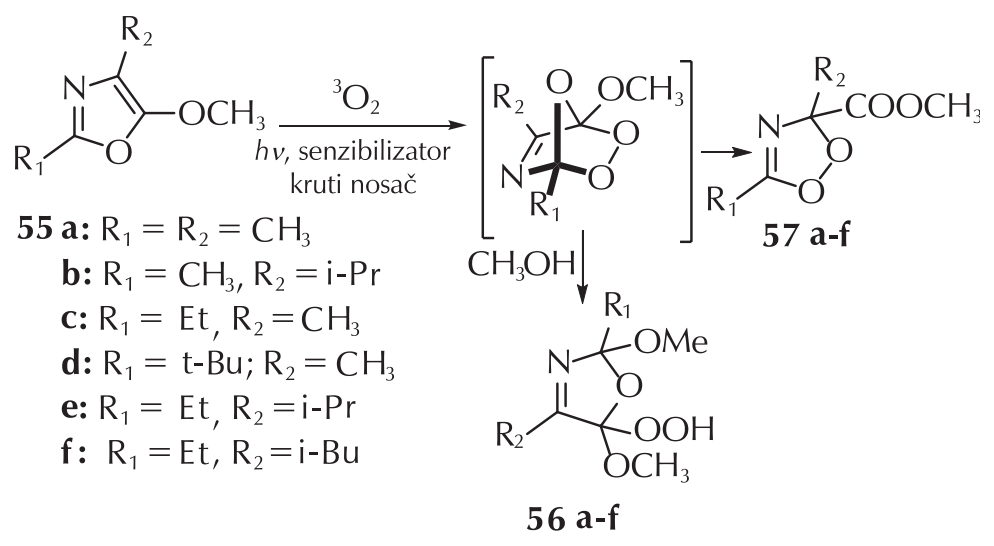

Shema 17 - Fotokemijske oksidacije oksazola u krutom stanju Scheme 17 - Photochemical oxidation reactions in solid state 
očekivano izolirali 5-(2,2-difeniletenil)-2,4-difeniloksazol (60) (shema 18).<smiles>Cn1c(I)c(-c2ccccc2)c(-c2ccccc2)c(-c2ccccc2)c1=O</smiles>

58<smiles>Oc1c(-c2ccccc2)nc(-c2ccccc2)c(-c2ccccc2)c1-c1ccccc1</smiles>

59<smiles>O=C1C(c2ccccc2)=NC(c2ccccc2)(c2ccccc2)C1c1ccccc1</smiles>

61

$$
h v
$$<smiles>C(=Cc1oc(-c2ccccc2)nc1-c1ccccc1)c1ccccc1</smiles>

60 a: $\mathrm{R}=\mathrm{OC}_{2} \mathrm{H}_{5}, \mathrm{R}^{\prime}=\mathrm{CH}_{3}$

b: $\mathrm{R}=\mathrm{OCH}_{3}, \mathrm{R}^{\prime}=\mathrm{C}_{2} \mathrm{H}_{5}$

c: $\mathrm{R}=\mathrm{C}_{6} \mathrm{H}_{5}, \mathrm{R}^{\prime}=\mathrm{C}_{6} \mathrm{H}_{5}$

62<smiles>[R]c1nc([Pb-])c([PH3-])o1</smiles>

63 a-c

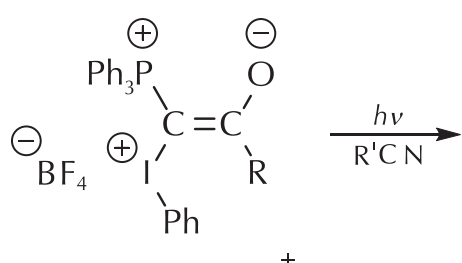

Shema 18 - Fotokemijska reakcija spoja $\mathbf{5 8}$

Scheme 18 - Photochemical reaction of compound $\mathbf{5 8}$

Praćenjem reakcije pomoću ${ }^{1} \mathrm{H}$ NMR spektara utvrdili su da oksazol 60 nastaje u dva slijedna fotokemijska koraka. Uspjeli su izolirati i međuprodukt 61. 3-piridone kao što je 58 moguće je promatrati kao aza-analoge cikloheksa-2,4-dienona. Pregrađivanje 58 u međuprodukt ide preko nastajanja veze između atoma C(3) i C(5) nakon kojeg slijedi migracija benzhidrilne skupine na atom C(6). Nastajanje hidroksipiridina 59 iz 61 je slično procesu fotopregrađivanja bicikloheksenonskog sustava u derivate fenola, točnije rečeno dolazi do migracije jedne od fenilnih grupa na atom C(1) nakon čega slijedi keto-enolna tautomerija. S druge strane, transformacija međuprodukta $\mathbf{6 1}$ u oksazol 60 nova je vrsta fotokemijskog pregrađivanja, čiji mehanizam još nije do kraja razjašnjen. Pretpostavlja se da karbonilni kisik napada atom $C(5)$, nakon čega dolazi do otvaranja tročlanog prstena. Reakcije su provedene i u krutom stanju pri čemu se omjer dva produkta pomiče na stranu nastajanja oksazola.

\subsection{Sinteza 2,4,5-trisupstituiranih oksazola}

Autori Matveeva i sur. ${ }^{41}$ 2009. godine novom fotokemijskom reakcijom između fosfonij-jodid-ilida $\mathbf{6 2}$ i alkil- i arilnitrila sintetiziraju 2,4,5-trisupstituirane oksazole (63-65) (shema 19).

Nakon što su isprobali mnoge "aktivatore", ne bi li potaknuli reakciju ilida i nitrila, slučajno su otkrili da UV zračenje drastično ubrzava taj proces. Istraživanjem reakcije otkrili su kako zamjena etoksi-karbonilne skupine na ilidu s fenilnom skupinom uvelike povećava reaktivnost ilida. Autori su istražili i opisali novu klasu fotokemijskih reakcija između miješanih fosfonij-jodid-ilida i nitrila u svrhu dobivanja polifunkcionalnih oksazola te su te reakcije optimirali.
$+\left(\mathrm{C}_{2} \mathrm{H}_{5}\right)_{2} \mathrm{~N}-\mathrm{CN}$<smiles>N#Cc1ccncc1</smiles>

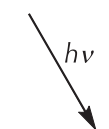<smiles>CCN(CC)c1nc(P)c(P)o1</smiles>

65<smiles>Pc1cccc(-c2nc(-c3ccncc3)oc2P)c1P</smiles>

Shema 19 - Fotokemijska sinteza polifunkcionalnih oksazola Scheme 19 - Photochemical synthesis of polyfunctionalized oxazoles

\subsection{Sinteza cis-i trans-4,5-dihidrooksazolskih derivata}

Sakurai i sur. ${ }^{42}$ proveli su prvu fotokemijsku sintezu cis- i trans-4,5-dihidrooksazolskih derivata $(67$ i 68$)$ iz alkilnih estera $N$-acil- $\alpha$-dehidroarilalanina (66). Sintetizirali su niz estera te su istražili utjecaj supstituenta, otapala i koncentracije trietilamina (TEA) na fotokemijsku reakciju. Dobili su kao produkte smjesu izomera.<smiles>[R20]C(=O)N/C(=C\[Al])C([R20])=O</smiles>

Shema 20 - Fotokemijska reakcija spoja 66 Scheme 20 - Photochemical reaction of compound $\mathbf{6 6}$ 
Omjer cis- i trans-produkata ovisi o koncentraciji TEA pri čemu povećanjem koncentracije raste udio trans-izomera u smjesi. Autori smatraju da se mehanizam reakcije nastanka dihidrooksazola može opisati mehanizmom fotoinduciranog prijenosa elektrona (PET).

\section{Popis simbola i kratica List of symbols and abbreviations}

\begin{tabular}{|c|c|}
\hline$q$ & $\begin{array}{l}\text { - gustoća } \pi \text {-elektrona } \\
-\pi \text {-electron density }\end{array}$ \\
\hline$q_{\mathrm{n}}$ & $\begin{array}{l}\text { - gustoća negativnog } \pi \text {-naboja } \\
-\pi \text {-charge density }\end{array}$ \\
\hline LCAO & $\begin{array}{l}\text { - metoda linearne kombinacije atomskih orbitala } \\
\text { - linear combination of atomic orbitals method }\end{array}$ \\
\hline CASSCF & $\begin{array}{l}\text { - samousklađeno polje s potpunim aktivnim prostorom } \\
\text { - complete active space self-consistent field }\end{array}$ \\
\hline $\mathrm{Cl}$ & $\begin{array}{l}\text { - stožasti presjek } \\
\text { - conical intersection }\end{array}$ \\
\hline${ }^{1} \mathrm{O}_{2}$ & $\begin{array}{l}\text { - singletni kisik } \\
\text { - singlet oxygen }\end{array}$ \\
\hline UV & $\begin{array}{l}\text { - ultraljubičasto } \\
\text { - ultraviolet }\end{array}$ \\
\hline TEA & $\begin{array}{l}\text { - trietilamin } \\
\text { - triethylamine }\end{array}$ \\
\hline PET & $\begin{array}{l}\text { - fotoinducirani prijenos elektrona } \\
\text { - photoinduced electron transfer }\end{array}$ \\
\hline
\end{tabular}

\section{Literatura \\ References}

1. I. J. Turchi, M. J. S. Dewar, Chemistry of oxazoles, Chem. Rev. 75 (1975) 389-437, doi: https://doi.org/10.1021/ cr60296a002.

2. I. J. Turchi, The Chemistry of Heterocyclic Compounds: Oxazoles, John Wiley and Sons, 1986., doi: https://doi. org/10.1002/9780470187289.

3. I. J. Turchi, Oxazole chemistry. A Review of Recent Advances, Ind. Eng. Chem. Prod. Res. Dev. 20 (1981) 32-46, doi: https://doi.org/10.1021/i300001a005.

4. H. H. Wasserman, K. E. McCarthy, K. S. Provse, Oxazoles in Carboxylate Protection and Activation, Chem. Rev. 86 (1986) 845-856, doi: https://doi.org/10.1021/cr00075a008.

5. A. Hassner, B. Fisher, New Chemistry of Oxazoles, Heterocycles 35 (1993) 1441-1465, doi: https://doi.org/10.3987/ REV-92-SR(T)6.

6. B. Iddon, Synthesis and Reactions of Lithiated Monocyclic Azoles Containing Two or More Hetero-Atoms. Part II: Oxazoles, Heterocycles 37 (1994) 1321-1345, doi: https://doi. org/10.3987/REV-93-SR9.

7. G. V. Boyd, Product Class 12: Oxazoles in Science of Synthesis, Category 2, vol 11, Georg Thieme Verlag Stuttgart, New York, 2002., str. 338-473.

8. D. C. Palmer, Oxazoles: Synthesis, Reactions, and Spectroscopy u E. C. Taylor, P. Wipf, The Chemistry of Heterocyclic Compounds; Part A, John Wiley and Sons Inc., New Jersey, 2003., str. 127-255, doi: https://doi. org/10.1002/0471428035.

9. E. Vedejs, Studies in Heteroelement-Based Synthesis, J. Org. Chem. 69 (2004) 5159-5167, doi: https://doi.org/10.1021/ jo049360l.
10. M. Schnürch, R. Flasik, A. F. Khan, M. Spina, M. D. Mihovilovic, P. Stanetty, Cross-Coupling Reactions on Azoles with Two and More Heteroatoms, Eur. J. Org. Chem. 15 (2006) 3283-3307, doi: https://doi.org/10.1002/ejoc.200600089.

11. J. W. Conforth, The Chemistry of Penicillin, Princeton University Press, Princeton, 1949.

12. G. Ya. Kondrat'eva, Khim. Nauka Prom. 2 (1957) 666.

13. R. A. Firestone, E. E. Harris, W. Reuter, Synthesis of pyridozine by Diels-Alder reactions with 4-methyl-5-alkoxy oxazoles, Tetrahedron 23 (1967) 943-955, doi: https://doi. org/10.1016/0040-4020(67)85043-9.

14. M. K. Orloff, D. D. Fitts, On the electronic structure of Oxazole, Tetrahedron, 19 (1963) 1691-1696, doi: https://doi. org/10.1016/S0040-4020(01)99242-7.

15. G. Berthier, R. Bonaccorsi, E. Scrocco, J. Tomasi, The electrostatic molecular potential for imidazole, pyrazole, oxazole and isoxazole, Theoret. Chim. Acta 26 (1972) 101-105, doi: https://doi.org/10.1007/BF00527659.

16. M. Roche, F. D'Amato, M. Benard, Structure électronique $\pi$ de l'Isoxazole, de l'oxazole et des oxadiazoles, J. Mol. Struct. 9 (1971) 183-189, doi: https://doi.org/10.1016/00222860(71)85019-6.

17. B. Singh, E. F. Ulman, Photochemical Transposition of Ring Atoms in Five-Membered Heterocycles. The Photorearrangement of 3,5-Diphenylisoxazole, J. Am. Chem. Soc. 88 (8) (1966) 1844-1845, doi: https://doi.org/10.1021/ ja00960a066.

18. B. Singh, E. F. Ullman, Photochemical transposition of ring atoms in 3,5-diarylisoxazoles. Unusual example of wavelength control in a photochemical reaction of azirines, J. Am. Chem. Soc. 89 (1967) 6911-6916, doi: https://doi. org/10.1021/ja01002a018.

19. J. P. Ferris, F. R. Antonucci, R. W. Trimmer, Mechanism of the photoisomerization of isoxazoles and 2-cyanophenol to oxazoles, J. Am. Chem. Soc. 95 (3) (1973) 919-920, doi: https:// doi.org/10.1021/ja00784a048.

20. J. P. Ferris, F. R. Antonucci, Chemical evolution. XVII. Mechanisms of the Photochemical Rearrangements of Ortho-Substituted Benzene Derivatives and Related Heterocycles, J. Am. Chem. Soc. 96 (1974) 2014-2019, doi: https://doi. org/10.1021/ja00814a006.

21. H. Tanaka, Y. Osamura, T. Matsushita, K. Nishimoto, An MO Study of the Reaction Mechanism of Photoisomerization from Isoxazole via Azirine Intermediate to Oxazole, Bull. Chem. Soc. Jpn. 54 (1981) 1293-1298, doi: https://doi. org/10.1246/bcsj.54.1293.

22. J. W. Pavlik, H. St. Martin, K. A. Lambert, J. A. Lowell, V. M. Tsefrikas, C.K. Eddins, N. Kebede, Photochemistry of 4- and 5- phenyl substituted isoxazoles, J. Heterocyclic Chem. 42 (2005) 273-281, doi: https://doi.org/10.1002/ jhet.5570420215.

23. M.-D. Su, Theoretical Investigations of the Photochemical Isomerizations of Indoxazene and Isoxazole, J. Org. Chem. 74 (2009) 6055-6063, doi: https://doi.org/10.1021/ jo901010q.

24. M.-D. Su, Mechanistic Analysis of an Isoxazole-Oxazole Photoisomerization Reaction Using a Conical Intersection, J. Phys. Chem. A 119 (2015) 9666-9669, doi: https://doi. org/10.1021/acs.jpca.5b07312.

25. R. H. Good, G. Jones, Syntheses with isoxazoles; the production of an isoxazolo[2,3-a]pyridinium salt, and the photochemical conversion of isoxazole-3-carboxylates into oxazole-2-carboxylates, J. Chem. Soc. C (0) (1971) 1196-1198, doi: https://doi.org/10.1039/j39710001196.

26. J. P. Ferris, F. R. Antonucci, Chemical evolution. XVI. Pho- 
tochemistry of ortho-substituted benzene derivatives and related heterocycles, J. Am. Chem. Soc. 96 (1974) 20102014, doi: https://doi.org/10.1021/ja00814a005.

27. C. M. Nunes, I. Reva, T. M. V. D. Pinho e Melo, R. Fausto, UV-Laser Photochemistry of Isoxazole Isolated in a Low-Temperature Matrix, J. Org. Chem. 77 (2012) 8723-8732, doi: https://doi.org/10.1021/jo301699z.

28. C. M. Nunes, I. Reva, R. Fausto, Capture of an Elusive Nitrile Ylide as an Intermediate in Isoxazole-Oxazole Photoisomerization, J. Org. Chem. 78 (2013) 10657-10665, doi: https:// doi.org/10.1021/jo4015672.

29. C. M. Nunes, S. M. V. Pinto, I. Reva, R. Fausto, Photochemistry of 3-amino-1,2-benzisoxazole: unexpected photoisomerization of an amino-spiro- $2 \mathrm{H}$-azirine to $1 \mathrm{H}$-azirine Tett. Lett. 57 (2016) 5038-5041, doi: https://doi.org/10.1016/j.tetlet.2016.09.098.

30. C. M. Nunes, S. M. V. Pinto, I. Reva, R. Fausto, On the Photochemistry of 1,2-Benzisoxazole: Capture of Elusive Spiro- $2 \mathrm{H}$-azirine and Ketenimine Intermediates, Eur. J. Org. Chem. 24 (2016) 4152-4158, doi: https://doi.org/10.1002/ ejoc. 201600668

31. D. W. Gamage, Q. Li, R. A. A. U. Ranaweera, S. K. Sarkar, G. K. Weragoda, P. L. Carr, A. D. Gudmundsdottir, Vinylnitrene Formation from 3,5-Diphenyl-isoxazole and 3-Benzoyl-2-phenylazirine, J. Org. Chem. 78 (2013) 11349-11356, doi: https://doi.org/10.1021/jo401819g.

32. S. Lopes, C. M. Nunes, A. Gómez-Zavaglia, T. M. V. D. Pinho e Melo, R.Fausto, Photochemistry and Vibrational Spectra of Matrix-Isolated Methyl 4-Chloro-5-phenylisoxazole-3-carboxylate, J. Phys. Chem. A, 115 (2011) 1199-1209, doi: https://doi.org/10.1021/jp110705c.

33. M. Kojima, M. Maeda, The photochemical rearrangement of 2,5-diphenyloxazole, Tet. Lett. 28 (1969) 2379-2381, doi: https://doi.org/10.1016/S0040-4039(01)88169-7.

34. M. Maeda, M. Kojima, Photorearrangement of 2-phenyloxazole, J. Chem. Soc., Chem. Comm. 15 (1973) 539-540, doi: https://doi.org/10.1039/c39730000539.
35. H. Tanaka, T. Matsushita, K. Nishimoto, A theoretical study on the photochemical transposition reaction of oxazole, J. Am. Chem. Soc. 105 (1983) 1753-1760, doi: https://doi. org/10.1021/ja00345a009.

36. J. Cao, Z.-Z. Xie, X. Yu, Excited-state dynamics of oxazole: A combined electronic structure calculations and dynamic simulations study, J. Chem. Phys. 474 (2016) 25-35, doi: https://doi.org/10.1016/j.chemphys.2016.05.003.

37. K. Gollnick, S. Koegler, [4+2]-cycloaddition of singlet oxygen to oxazoles formation of oxazole endoperoxides, Tet. Lett. 29 (1988) 1003-1006, doi: https://doi.org/10.1016/00404039(88)85319-X.

38. K. Gollnick, S. Koegler, Thermal transformations of oxazole endoperoxides: Rearrangements, fragmentations and methanol additions, Tet. Lett. 29 (1988) 1007-1010, doi: https:// doi.org/10.1016/0040-4039(88)85320-6.

39. A. G. Griesback. T. T. El-ldreesy, Solvent-free photooxygenation of 5-methoxyoxazoles in polystyrene nanocontainers doped with tetrastyrylporphyrine and protoporphyrine-IX, Photochem. Photobiol. Sci. 4 (2005) 205-209, doi: https:// doi.org/10.1039/b416159a.

40. Y. Mori, K. Maeda, Novel photochemical rearrangement of 2,4,4,6-tetraphenylpyridin-3(4H)-one to an oxazole derivative, J. Chem. Soc., Chem. Commun. (17) (1991) 12001201, doi: https://doi.org/10.1039/c39910001200.

41. E. D. Matveeva, T. A. Podrugina, A. S. Pavlova, A. V. Mironov, R. Gleiter, N. S. Zefirov, Novel Photochemical Reactions of Phosphonium-lodonium Ylides: Synthesis of Phosphonium-Substituted Oxazoles, Eur. J. Org. Chem. 2009 (14) (2009) 2323-2327, doi: https://doi.org/10.1002/ ejoc. 200801251.

42. K. Maekawa, N. Hishikawa, K. Kubo, T. Igarashi, T. Sakurai, Preferential formation of cis-4,5-dihydrooxazole derivatives via photoinduced electron transfer-initiated cyclization of $\mathrm{N}$-acyl- $\alpha$-dehydroarylalanine alkyl esters, Tetrahedron 63 (2007) 11267-11281, doi: https://doi.org/10.1016/j. tet.2007.08.089.

\section{SUMMARY \\ Excited State Reactions of Oxazoles and Their Derivatives. Part I: Phototranspositions in the Ring Ivana Šagud* and Marija Šindler-Kulyk}

Heterocyclic compounds are a very important part of organic chemistry. Oxazole is a five-membered heterocycle with nitrogen and oxygen atoms in the ring. Oxazole is part of complex structures used in medicinal chemistry, pharmacology, and material chemistry. In the excited state, the oxazole ring can rearrange itself via several reaction mechanisms. In this paper, an extensive literature overview is given for photoisomerisations (phototranspositions) in oxazole, isoxazole, and benzisoxazole ring. A literature review is also given for phototransformations of the ring in the presence of oxygen (photooxygenation reactions), as well as for photoformation of the oxazole ring.

\section{Keywords}

Oxazole, photochemistry, heterocycles, isomerisation, photooxygenation

Faculty of Chemical Engineering and Technology

University of Zagreb, Marulićev trg 20

10000 Zagreb, Croatia
Review

Received March 14, 2017 Accepted May 1, 2017 